\title{
A Espacialidade do Melancólico - Parte I
}

\section{Primeira Comunicação}

\author{
Sobre as Alterações da Vivência Espacial na Melancolia Endógena
}

\author{
Hubert Tellenbach
}

\section{PUBLICADO ORIGINALMENTE EM “DER NERVENARZT”, 27 (7), 1956, pp. 12-18.}

Resumo: São descritas alterações da vivência espacial em três pacientes com melancolia endógena. Após a exposição dos pressupostos metodológicos, que estão dados na compreensão de espaço de Kant e Leibniz, faz-se a análise dos distúrbios. Há alterações na vivência do espaço circundante natural e orientado e do "espaço interior". Uma tentativa de explicar esses distúrbios a partir de pressupostos metodológicos (categoriais) da vivência espacial leva a contradições insolúveis. Estas levam a questionamentos, dentre os quais, formulam-se alguns.

\begin{abstract}
The article describes spatial experience (Erleben) alterations in three patients suffering from endogenous melancholia. After presenting the methodological premises, given in Kant's and Leibniz's space theories, it analyses the disorders. There are alterations in the experience of the natural oriented surrounding space and the "inner space". An attempt to explain these disorders from methodological (categorial) premises leads to unsoluble contradictions. These contradictions raise questions, and some of them are formulated.
\end{abstract}

Desejamos preencher uma lacuna que ficou aberta na psicopatologia descritiva das psicoses endógenas. Em duas profundas análises, F. Fischer (1930) dissertou sobre as alterações das vivências temporal e espacial nas psicoses esquizofrênicas. No que diz 


\section{Hubert Tellenbach}

respeito à melancolia endógena, até agora só se apresentaram as alterações da vivência temporal (E. Minkowski, E. Straus, V. v. Gebsattel, G. Kloos). Ainda faltavam relatos sobre as alterações da vivência espacial. Não era de se esperar que a vivência espacial não estivesse incluída na profunda transformação vivencial que há na melancolia endógena; no entanto, experimenta-se a alteração dessa vivência muito raramente - por motivos sobre os quais ainda falaremos ${ }^{1}$.

I.

1. Na paciente Th. H., que há muito já era preocupada e séria, mas também se mostrava aberta e tinha uma vida ativa e satisfeita, começaram a se desenvolver em novembro de 1952 sentimentos de fraqueza e tristeza, cuja origem era misteriosa até para ela mesma. Sobrevieram medos e ansiedades (como se o peito fosse estreitado por um "aperto" e nada mais pudesse passar pela garganta). O sentimento de completa incapacidade corpóreopsíquica ocasionalmente escalava para curtos estados de inércia. Por fim, a paciente vivenciou uma completa alteração de si mesma e do mundo. Nesse estado terrivelmente doloroso, ela foi internada em 12/03/53 na Clínica Psiquiátrica da Universidade de Munique.

O prontuário (234/53) registra, entre outros elementos, os seguintes: a paciente perdeu toda a alegria de viver e quaisquer interesses; tinha um medo interior, primeiramente como uma sensação que subia do meio do peito para a garganta (como um corpo estranho mais ou menos do tamanho da ponta de um dedo, que ela tentava expelir tossindo), mais tarde como uma sensação no peito de vazio, de oco. Dormia mal, resmungava dia e noite sobre sua doença e a mudança que veio com ela; não tinha mais ânimo para trabalho nenhum. Também tinha a impressão de que todo o mundo tinha se alterado. "Não tenho mais nos ossos a energia que me empurra para baixo. Não consigo mais sair do lugar. Quando estou na cama, tenho a sensação de que flutuo no ar em torno dela, como quando estou na banheira". Quando anda, tem a impressão de estar pequena,

\footnotetext{
${ }^{1}$ Na segunda comunicação.
} 


\section{A espacialidade do melancólico - Parte I}

como se estivesse comprimida; sente que é impossível avançar. "Como se eu estivesse presa... num pântano"... “Eu simplesmente não consigo mais imaginar nada. Meu marido e meus filhos, é como se jamais os tivesse visto"... “De resto, quando olhava através da janela, a natureza... nela tudo soava tão belo e havia um ar tão bom, mas agora nada lá se move mais. Quando vejo alguém dirigindo uma bicicleta, é como se estivesse parado". Na verdade, a pessoa se moveria, mas "é como se eu não vivesse o dia, como se estivesse na eternidade e não pudesse morrer, de tão pesado que está por dentro. Isso aperta tanto o peito todo que todas as coisas parecem estar sobre ele.”.... “O sentimento está morto por dentro. Por exemplo, se um de meus filhos morrer hoje, eu não darei por falta. Se me escrevessem a respeito, eu choraria, mas eu simplesmente não dou por falta. Quando caio no sono, é como se houvesse um grande corte pelo corpo. Então abro os olhos rapidamente para ver outras pessoas; aí me sinto melhor. Quando um avião voa por cima de mim, agora ele zune também dentro de mim, dos ossos. Muitas vezes disse para meu marido que é como se eu visse menos pelo olho direito. É como se tivesse mais sensibilidade à esquerda. Como se uma rede se colocasse na frente de tudo". A visão, a audição, as cores, o paladar, tudo estaria mais apagado, menos colorido. "No começo parecia que havia coisas demais no meio do corpo, mas depois era como se estivesse completamente vazio". "Tenho a impressão de que meu corpo está muito pequeno, e eu não consigo viver o dia de maneira significativa”. "Tudo me pressiona assim de baixo para cima”. Embora algumas vezes estivesse em uma cadeira macia, já teve a sensação de que a cadeira não conseguiria se soltar de seu corpo. Quando sonhando ou desperta, via as pessoas como "as sombras na parede. Tudo se movimenta tão lentamente que parece parado. Como se tudo fosse arrancado de mim". Ela não sabia se as coisas tinham relação com seu interior. "Eu sou como um pedaço de madeira assim". Via todos os objetos ao mesmo tempo, sem contornos fixados, sem relação uns com os outros. "Como se flutuassem livremente no espaço". Via os números do relógio separadamente, "como se estivessem livres no ar". Não conseguia mais avaliar distâncias e com frequência as coisas pareciam muito pequenas a seus olhos. "A partir daqui" - indica o meio do peito - "tudo sai do lugar quando eu como. Quando falo, não o faço na minha linguagem natural. A partir desse lugar tudo escorre. Não consigo me alegrar, nem me enfurecer, porque não tenho quase nenhuma energia. Por exemplo, construímos uma casa para nós, mas só posso 


\section{Hubert Tellenbach}

imaginá-la como se ela flutuasse sobre a água". Quer dizer que a casa como que passava por ela flutuando sobre a água. A imaginação só consegue recriá-la por um momento, mas logo ela se vai "como se estivesse flutuando numa torrente". Via tudo apenas com os olhos do entendimento, não mais com os do sentimento. Sempre ofegava puxando o ar de baixo para cima, pensa que agora respira o ar a partir de baixo, não mais livremente, de todos os lados. Uma vez disse que tivera a impressão de ao mesmo tempo respirar com uma narina e expirar com a outra e de não ter respirado "Simplesmente tudo evapora no ar. Quando tusso, a tosse se reparte rapidamente no ar, como se eu não houvesse tossido".

Mais tarde, em outro questionamento, a paciente informa, entre outras coisas, o seguinte: quando fecha os olhos, se sente como se de repente estivesse muito longe; então escancara os olhos de pavor e se sente melhor. Não consegue conversar com as pessoas. "Ainda ouço as pessoas como antes, mas o que ouço e penso é delgado demais para que eu possa pegá-lo". No espaço, tudo o que é vivo cessara de soar agradável como soava antes, tudo estaria excessivamente delgado. Todo o sentimento de tempo teria desparecido. “Eu percebo a passagem do tempo, mas não a vivencio. Sei que amanhã será um dia, mas não o sinto chegar. Consigo estimar o passado em termos de anos, mas não tenho mais qualquer relação com ele. A imobilidade do tempo é infinita, vivo numa eternidade estática. Vejo que os relógios giram, mas para mim o tempo não passa". Também seu corpo não seria mais como antes. “As mãos já não são tão firmes como antes, o dinheiro e os outros objetos parecem mais pesados nas minhas mãos. Não consegui mais erguer meu filho da cama; era muito pesado. Dentro de mim tudo está diferente. Sou como uma casa cuja fachada está em pé, mas cuja parede traseira ruiu."... "Tudo está em uma só linha, não há mais diferença de profundidade. Já não consigo ter nada determinado em vista. Sinto-me como uma boneca de olhos de vidro. Vejo tudo, mas não consigo me concentrar em nada. Não consigo mais imaginar meus filhos, mas preciso ficar sempre olhando as fotografias... Tudo parece uma superfície plana firme".

Depois de dez aplicações de eletrochoque, as queixas foram deixadas de lado, e só ficou um pequeno resíduo social-atmosférico (sozial-atmosphärisch). A paciente virara novamente uma mulher carinhosa e aberta. 


\section{A espacialidade do melancólico - Parte I}

2. A paciente A. D., nascida em $21 / 02 / 1897$ (prontuário 106/55), já passara por três fases quando foi internada na Clínica Psiquiátrica da Universidade de Munique pela primeira vez em 1948. Ela é uma freira e professora muito culta e, sobretudo, talentosa com idiomas. Sempre foi extraordinariamente sensível e muito dada a se culpar. Em todas as estadias na clínica (em 1955 era a terceira), estava no centro de sua vivência um grotesco delírio de pecado, um delírio de grandeza de pecado, por assim dizer ("dois bilhões de pecados mortais", entre outras afirmações). A isso se somaram todos os sintomas clássicos da depressão endógena: pronunciados fenômenos de desrealização e despersonalização, forte tristeza, em parte inibição, em parte agitação, distúrbios vitais, graves alterações na vivência temporal com regressão ao passado. Os estados graves de depressão cessaram após 6-8 aplicações de eletroconvulsoterapia.

No auge da psicose, a paciente fazia as seguintes queixas, entre outras: "Quando escrevo, também as teclas chegam ao cérebro. O cérebro cai para frente, e eu tenho que o colocar de novo no lugar." - nisso a paciente faz um gesto de empurrar com as mãos, do nariz até a testa. "Só me restou um quarto de cérebro; o resto está gagá".

A paciente estava tão atormentada, que era muito difícil abordá-la com questionamentos. Quando foi examinada, uma semana após sua alta, estava em leve flutuação hipomaníaca, com grande disposição ao diálogo possivelmente ligada a uma fuga de ideias e com humor otimista. Conseguia dar informações abrangentes, muito determinadas e exatas sobre suas vivências. Atribuía o fato de poder fazê-lo aos exames de consciência diários que praticava há muitas décadas.

A paciente tinha sobretudo distúrbios na vivência espacial, que começaram com o adoecimento inicialmente abrupto, permaneceram por sete meses e depois não mais apareceram de maneira tão pronunciada. Já antes (1948) contara que de repente vira o mundo circundante como se fosse apenas uma superfície plana, sem plasticidade, “como uma pintura", de modo que não estava mais certa da realidade desse mundo e sentia a necessidade de tocar tudo antes, até mesmo pessoas. Além disso, teria sentido "seus olhos como corpos estranhos nas cavidades oculares" e tido uma sensação pavorosa de vazio na cabeça. 


\section{Hubert Tellenbach}

Agora a paciente relatou o seguinte, de maneira coerente: naquela época (1933), teria sentido repentinamente um rasgo atrás da cabeça. Unir-se-ia a isso a sensação de estar em um outro planeta. "Nesses momentos, eu sabia que estava aqui em meio às pessoas, mas internamente estava longe, muito longe"... “Era como se minha alma ou meu coração estivessem muito longe". "Eu tive a impressão de que, no momento em que houve o rasgo, estava rompida qualquer ligação interior entre mim e as outras pessoas. Não conseguia entender os outros e eles não conseguiam me entender". Assim, houve uma espécie de deslocamento mental ligado a uma vivência idiossincrática do espaço. Ela via tudo a seu redor como uma superfície plana. “Vejo tudo como uma superfície plana; nada mais recua em profundidade. Também as pessoas eram uma superfície plana. Eu tinha que tocar tudo: os objetos no espaço, os cantos e as extremidades, para me convencer de que tinham mais dimensões. Também tinha que tocar as pessoas para verificar se elas eram apenas uma superfície. Quando uma irmã entrava no meu quarto, ela me parecia uma superfície”. "Eu não estava mais ligada às pessoas e, no entanto, ainda estava lá; não tinha qualquer sentimento mais dentro de mim". “Eu não via mais qualquer rotundez; tudo era plano. Via, por exemplo, as árvores como as que as crianças pequenas desenham: simplesmente dois traços, sem rotundez" ... "Tudo era uma única superfície plana. Também as coisas em primeiro plano, não as via mais em primeiro plano, mas como se estivessem, por assim dizer, coladas nessa superfície. Creio que também não conseguia estimar as diferentes distâncias entre mim e essa superfície. Eu conseguia estimar a distância entre mim e ela, mas não entre mim e as coisas que estavam ali". Em contrapartida, ainda era possível ver e estimar os intervalos entre as coisas que estavam sobre a superfície. “Os objetos em particular que estavam colados na parede não tinham qualquer relação interior entre si. Ficavam completamente isolados, sem qualquer relação recíproca"... "Eu tocava também a mim mesma para, por exemplo, verificar se os braços tinham rotundez, pois eu não a via. Naquela época, eu vi e vivenciei até a mim mesma como superfície plana" ... “Eu também não conseguia apanhar nada em separado para observar de perto. Tudo estava em uma superfície, justaposto e enovelado. Sempre ficava andando em torno do meu quarto, tocando tudo e verificando se era espaço mesmo. Ficava tocando até mesmo as pessoas, sempre com o mesmo assombro. Dentre a variedade 


\section{A espacialidade do melancólico - Parte I}

de coisas que estava a minha volta, não conseguia mais apanhar nenhum objeto determinado"... "Essa situação durou sete meses e lentamente regrediu. De repente passei a ver tudo novamente e senti a mim mesma como uma pessoa normal de novo. Gradativamente, depois de tanto tocar os objetos, me acostumei a pensar que somente as árvores eram superfície plana. O tato sempre me disse que as coisas eram rotundas ou tinham profundidade. Somente a visão era plana".

Os espaços (igrejas, jardins etc.) todos tinham perdido sua atmosfera (Stimmung). “Tudo era vazio e desolado". Não se podia dizer que o espaço tinha uma atmosfera (Stimmung) ameaçadora, mas antes estranha e sem essência.

3. A paciente M. B., de 47 anos, uma empregada doméstica em média não muito talentosa, mas bastante ambiciosa, cheia de aspiração e sensível, era desde sempre dada a preocupações. Era tímida por conta de um sentimento de inadequação e por isso também não se casou. Aos vinte anos, fez uma tonsilectomia por conta de uma singular disfagia (na fase larvar?), aos trinta e dois, uma tireoidectomia, porque "sempre tinha a sensação de um caroço na garganta" e, além disso, se sentia "muito triste". Há dez anos, teve por um longo tempo um singular formigamento nas pernas (houve uma internação de oito semanas, sem resultado), também ficou de ânimo pesaroso por um tempo. Por causa da crescente tristeza, foi em outubro de 1954 a uma clínica psiquiátrica. Ali se acreditava "condenada" pelos médicos e pelas enfermeiras. Por toda parte via insinuações de sua morte, de que viria em breve; por fim, acreditava que teriam "derramado nela uma coisa preta", pela qual ela certamente morreria. Temerosa, ela foi rapidamente para casa, onde

ficou se lamentando por muito tempo, culpou os pais por sua doença e profetizou-lhes que morreriam em breve. Além disso, comia notoriamente muito e tirava a comida dos outros sem se envergonhar.

A paciente demonstra aqui o quadro de uma depressão queixosa com tristeza corporificada, distúrbios vitais, inibição grave, delírio de pecado, distúrbios na vivência temporal e espacial. Ademais, é dependente de relacionamentos e vê no comportamento do mundo circundante uma permanente confirmação de sua condenação. Ela diz o seguinte em detalhes (com esforço e lutando contra a inibição): "Sempre me vem o 


\section{Hubert Tellenbach}

pensamento de que sou má; sou obrigada a acreditar nele, mesmo que não queira". Não consegue mais rezar, a consciência lhe diz que ela recebeu os sacramentos sem merecê-los. “Não me confessei corretamente, ninguém pode tirar-me os pecados! Então as pessoas podem me condenar? Isso não está no catecismo, eu não sabia, mas existe, pois, no hospital, colocaram na minha cama um cartaz com anéis e manchas muito pretos, que eles me deram porque minha alma está perdida. Eu teria somente que me converter, gostaria de me converter, se apenas soubesse como". O motivo da condenação seria que meninos da escola a teriam "corrompido" e que coisas impuras teriam sido feitas com ela. Agora sempre pensa nisso; só consegue pensar no passado; na verdade, não consegue mais pensar porque tudo nela está vazio. Não consegue imaginar o presente e o futuro. “Há um aperto constante no peito. Ali fica a preocupação; é tão pesado; queima e aperta como se o peito estivesse ao mesmo tempo cheio e vazio". "A sensação se alterou em todo o corpo; tudo está tão duro quanto um tijolo... Primeiro há uma sensação estonteante nos pés; isso circula pelo corpo e também pela cabeça. Não consigo mais pensar em nada, dentro da cabeça é tão estranho e opaco. Estou tão tonta; eu queria me sentir de maneira diferente". Sente continuamente "uma forte pressão na bexiga". A todo momento sente pinicadas e comichões na genitália. Um médico lhe disse que ela tem uma doença venérea. Ele viu isso nela apenas por fora. "As pessoas sabem tudo a meu respeito, me escarnecem e desviam o olhar de mim. Também as enfermeiras do hospital sempre desviam o olhar de mim, e aqui todas as pessoas mostram a língua para mim, e tem sido assim o tempo todo".

Nos últimos tempos sentiria a necessidade de comer mais, embora não tivesse apetite. "Mas sempre acho que estou com fome; eu como mais do que antes para o tempo passar e porque está tudo vazio aqui dentro".

“Tudo está diferente ao meu redor; o tempo passa muito lentamente, a noite dura muito, uma hora dura tanto quanto um dia durava antes. Tudo está morto ao meu redor; se alguém pudesse me ajudar... Tudo está tão vazio e tão noite; nenhuma luz; o sol não brilha mais como antes. E não tenho mais nenhum sentimento em relação às pessoas; tudo está vazio e morto dentro de mim". Algumas vezes o tempo parou; foi muito assustador. 


\section{A espacialidade do melancólico - Parte I}

Também o espaço se alterou: “Tudo está tão vazio e escuro, tudo está tão distante de mim. Vejo tudo tão distante como se estivesse num outro povoado ou numa outra cidade. Não vejo como antes; vejo tudo como se fosse apenas o segundo plano; tudo é como uma parede, tudo é plano. Tudo me pressiona para baixo, todos desviam o olhar de mim e riem". Quando confrontada com um desenho bidimensional e outro tridimensional da vista da janela e perguntada a respeito de sua vivência, aponta decididamente para o desenho sem perspectiva. No entanto, consegue reconhecer os contrastes de perto em sua plasticidade total.

Depois de alguns eletrochoques, a paciente já melhorou significantemente. Não consegue dar dados detalhados sobre seu distúrbio da vivência espacial, evidentemente por conta de dificuldades de expressão. A vivência do pecado ainda está em primeiro plano para ela.

\section{Pressupostos de uma análise da vivência espacial}

Quando o psicopatologista toma "o espaço" como tema, na maior parte das vezes ele se baseia (de maneira inconsciente ou não expressa) no conceito de espaço de Kant. Com isso, ele adquire a vantagem de uma diferenciação muito sofisticada e útil dos diversos lados do espacial. Em Kant, o espaço (assim como o tempo e as categorias) é em primeiro lugar um fundamento cognitivo. Ele não é "propriedade de qualquer coisa em si ", isto é, não é uma determinação inerente aos próprios objetos, mas apenas uma "forma de intuição (Anschauung)2", ou "uma representação (Vorstellung) 3 a priorit, que, por necessidade, é o fundamento dos fenômenos exteriores"; ou também: "a condição subjetiva da sensorialidade, somente sob a qual a intuição exterior nos é possível”.

\footnotetext{
${ }^{2}$ N. do T. : Termo utilizado por Kant para se referir às representações (ver abaixo) que trazem à mente os objetos apreendidos pela sensorialidade.

${ }^{3}$ N. do T. : Termo usado por Kant para se referir às experiências mentais (conceitos, intuições, sensações, percepções).

${ }^{4}$ N. do T.: Termo empregado por Kant para se referir ao conhecimento que antecede e é independente da experiência.
} 


\section{Hubert Tellenbach}

Uma vez que para toda intuição dependemos da sensorialidade, uma pessoa que não possuísse nenhum sentido também não teria a condição subjetiva da sensorialidade, isto é, o espaço como a priori. Com isso, tal pessoa estaria privada não somente de todo dado espacial, mas também de qualquer possibilidade de conhecimento. A psicopatologia, portanto, não pode descrever qualquer situação em que o "espaço" simplesmente esteja ausente. Também não se pode descrever a "ausência do espaço" porque não conseguimos nem pensar, nem imaginar semelhante situação. Na melhor das hipóteses, conseguimos pensar um espaço vazio, ainda que não o consigamos imaginar.

A situação é outra no que tange às maneiras de concepção dos espaços (empíricos), possibilitadas pelo a priori espacial. Aqui, a psicopatologia pode muito bem descrever situações em que o espacial existe de maneira alterada. Ela pode distinguir entre casos em que a alteração do espaço é sentida conscientemente (por exemplo, as nossas pacientes) e outros em que a consciência da alteração está ausente (por exemplo, em algumas alterações das funções corticais ${ }^{5}$ ). Kant também apresenta as características do espaço empírico, como ele se nos manifesta na representação a priori. O espaço tem "três dimensões", é "uno" e "infinito". Esses dados do espaço empírico são como que a moldura dentro da qual se vivencia e se conhece o espacial como algo em particular.

A vivência consciente do espaço dado está sobretudo ligada a certas articulações do espacial na ordenação do mundo das coisas. Kant oferece apenas uma definição extremamente simples, na seguinte sentença: "Todas as coisas são adjacentes no espaço". No entanto, para a vivência - e consequentemente, para o psicopatologista -, é importante sobretudo o modo dessa adjacência. Vivenciamos o espaço relativamente às coisas que o preenchem. Por isso, ao psicopatologista que se ocupa da vivência espacial mostram-se úteis antes os princípios espaciais de Leibniz, aos quais remonta a doutrina kantiana da fenomenalidade pura do espaço. Para Leibniz, o espaço existe somente "na verdade das relações entre as coisas". O espaço não é outra coisa que não "uma ordenação para a existência das coisas", ou uma "ordenação segundo a qual as coisas são organizadas".

\footnotetext{
${ }^{5}$ Não levaremos em questão em que medida vivências espaciais alteradas podem existir em ou preceder situações de desorientação no espaço - ou se o espaço dado anteriormente como tal é apreendido de maneira inalterada.
} 


\section{A espacialidade do melancólico - Parte I}

Enquanto as definições de espaço kantianas fundamentam sobretudo o a priori do espaço e sua distinção do espaço empírico, por meio do conceito de espaço de Leibniz, que transcende a mera adjacência das coisas, fundamenta-se a estrutura do espaço orientado, tomado como um sistema de ordenações, relações e referências entre o eu-corpo e as coisas.

Os pressupostos principiais de nossa análise têm, portanto, natureza e origem duplas. Enquanto relacionamos as alterações no dado espacial às psicoses tomadas como distúrbios do "sujeito", pressupomos (ainda que de maneira não expressa) as doutrinas do espaço de Kant como condição subjetiva de toda sensorialidade - de certo modo, como uma forma anterior dada a priori à vivência. Contudo, enquanto queremos descrever o distúrbio da vivência do espaço, no sentido de uma alteração na ordenação das coisas no mundo, fora do sujeito, mostra-se útil antes a visão de Leibniz sobre o espaço.

\section{Alterações na vivência do espaço orientado}

A psicopatologia descritiva trata na maior parte das vezes o espaço como a vivência do que momentaneamente nos cerca, o que, na condição de "espaço orientado" (O. Becker) ou "espaço dirigido a um fim" (E. Straus), pertence ao "espaço do mundo natural" (L. Binswanger).

Na vivência natural desse espaço, eu tomo meu eu, meu corpo, como o meio, como "o aqui absoluto para qualquer lá" (L. Binswanger'6). Em oposição aos objetos espaciais do lá, do "espaço circundante", meu corpo, na condição de figura igualmente espacial, assume uma posição preferencial. O espaço circundante (no qual me oriento a partir de meu corpo, que eu constantemente "levo junto" comigo) se constitui essencialmente, do ponto de vista da visualidade, como espaço tridimensional. Eu posso agarrá-lo com meu olhar, apanhá-lo com meus passos. “Em meu lugar, estou ciente” dele (Jaspers). A partir desse lugar, eu o articulo em direita e esquerda, cima e baixo, perto e longe. Dentro dessa

\footnotetext{
6 Note-se expressamente que L. Binswanger não formula assim a concepção de espaço própria, mas a
} convencional. 


\section{Hubert Tellenbach}

articulação, posso fazer estimativas de distância. É digno de nota que consigo estimar a distância entre mim e os objetos com maior certeza do que a distância entre eles. Por fim, eu consigo perceber e vivenciar as mudanças de lugar das coisas como movimentos no espaço.

A tentativa de analisar as alterações na vivência do espaço orientado dado naturalmente levaria primeiramente à constatação de que, nos pacientes, essa experiência toma como pano de fundo o conhecimento remanescente (embora abstrato) de como é a intuição do espaço nos dias saudáveis. É de fato a alteração dessa intuição que os pacientes vivenciam tão dolorosamente. Ao contrário daqueles com "alterações nas funções corticais", no sentido empregado por J. Lange, os pacientes estão cientes, por assim dizer, da medida correta, mas são compelidos a utilizar outras medidas.

Entre as alterações na vivência do espaço circundante orientado, ressalta-se especialmente uma perda da dimensão da profundidade. Os pacientes não conseguem mais vivenciar a profundidade espacial.

“Tudo está em uma só linha... Tudo parece uma superfície plana firme” (paciente I, Th. H.). Uma casa tem apenas a fachada, mas não a profundidade. A própria paciente é uma superfície plana. "Sou como uma casa cuja fachada está em pé, mas cuja parede traseira ruiu". Dessa mesma maneira, a paciente II, A. D. vê as coisas, as pessoas e a si mesma de maneira plana. Ela toca tudo para se assegurar da profundidade, da rotundez e das extremidades por meio da vivência tátil (que permanece sem distúrbio). “Via, por exemplo, as árvores como as que as crianças pequenas desenham: simplesmente dois traços, sem rotundez ... Também as coisas em primeiro plano, não as via mais em primeiro plano, mas como se estivessem, por assim dizer, coladas nessa superfície".

Também a paciente III, M. B. se queixa da perda da profundidade espacial. "Não vejo como antes; vejo tudo como se fosse apenas o segundo plano; tudo é como uma parede, tudo é plano".

Nesses relatos, mostra-se o distúrbio da articulação do espaço em longe e perto, 


\section{A espacialidade do melancólico - Parte I}

ocorrido juntamente com o desaparecimento da vivência da profundidade. As coisas se deslocam e saem do primeiro plano em direção a uma superfície plana pela qual o horizonte rotundo é substituído, como nas projeções sobre uma tela.

Essa vivência ficará ainda mais clara se, no espaço orientado, diferenciarmos o espaço corpóreo e o espaço do mundo circundante - no sentido de "pólos funcionais correspondentes" (L. Binswanger).

Na paciente II, A. D, o espaço do mundo circundante se desprende do espaço corporal, perde o contato com ele.

Também a paciente III, M. B., se queixa de que tudo se afasta dela. “Tudo está tão vazio e escuro, tudo está tão distante de mim. Vejo tudo tão distante como se estivesse num outro povoado ou numa outra cidade". Em concordância com isso, também há distúrbio na capacidade de estimar a distância entre as coisas. A paciente I, Th. H., diz que com frequência vê as coisas como se fossem bem pequenas e só sabe de memória qual seria a distância entre os objetos. A paciente II, A. D., consegue estimar a distância até o horizonte plano, mas não a distância até as coisas e o intervalo entre elas, no entanto, pode fazê-lo com as distâncias delas na projeção sobre a superfície plana.

Ao mesmo tempo, também houve alterações na percepção correspondentes a esses fenômenos: um distúrbio na visão predicativa, na percepção visual no sentido estrito.

A paciente I, Th. H., vê as pessoas como "sombras na parede", vê as coisas "ao mesmo tempo, sem contornos fixados... Já não consigo ter nada determinado em vista... Vejo tudo, mas não consigo me concentrar em nada". Uma visão que já não consegue ter nada em particular em vista necessariamente vê tudo "ao mesmo tempo", não consegue dar às coisas particulares contornos fixados, não consegue convergir para o particular, se "concentrar".

A paciente II, A. D., também vivenciou essa alteração da visão: “Eu também não conseguia apanhar nada em separado para observar de perto. Tudo estava em uma superfície, justaposto e enovelado... Dentre a variedade de coisas que estava a minha volta, 


\section{Hubert Tellenbach}

não conseguia mais apanhar nenhum objeto determinado". A paciente I, Th. H., se serve de uma comparação extremamente pictórica para explicar essa vivência: "Sinto-me como uma boneca de olhos de vidro", ao que corresponde a afirmação da paciente II , A. D., de que "sentia seus olhos como corpos estranhos".

No caso da paciente I, Th. H., encontramos ainda uma alteração bastante marcada da vivência espacial que se relaciona com a estruturação espacial de cima e baixo que há na diferenciação entre leve e pesado. O corpo não credita seu significado central último no espaço orientado à segurança com que ele, por força da gravidade, assume sua posição. Em nossa paciente, essa vivência natural do peso, de sua direção efetiva de cima para baixo, decididamente sofre um distúrbio. Ela mesma perdeu seu posto firme e, com ela, também as coisas o perderam. "Não tenho mais nos ossos a energia que me empurra para baixo... Quando estou na cama, tenho a sensação de que flutuo no ar em torno dela, como quando estou na banheira". "Construímos uma casa para nós, mas só posso imaginá-la como se ela flutuasse sobre a água". A gravidade parece dar temporariamente lugar à levitação. "Tudo me pressiona assim de baixo para cima". Ela sempre ofega "puxando o ar de baixo para cima". O ar sobe de baixo para cima. Mesmo a cadeira não quer mais ir para baixo. É o sentimento da perda do próprio peso, o sentimento de uma corporeidade tão delgada e leve, que ela é até mesmo "comprimida" pela atmosfera (Atmosphäre) e dá impressão de ser "muito pequena". Essa vivência do distúrbio da direção efetiva do peso é tão imperativa que a sensibilidade muscular se deixa enganar. "As mãos já não são tão firmes como antes, o dinheiro e os outros objetos parecem mais pesados nas minhas mãos... Não consegui mais erguer meu filho da cama; era muito pesado".

Na outra paciente, por sua vez, predominava o sentimento de ser pressionada para baixo. “Tudo me pressiona para baixo" (paciente III, M. B.). Também a paciente II, A. D., relatou que às vezes tinha a sensação de que tudo lhe era uma carga e de que mesmo o teto ameaçava desabar sobre ela7.

Além das alterações na vivência da estrutura espacial de perto e longe, cima e

\footnotetext{
${ }^{7}$ N. do T.: Essa informação não consta no relato apresentado anteriormente.
} 


\section{A espacialidade do melancólico - Parte I}

baixo, na paciente I, Th. H., também se sugere um desequilíbrio na vivência de direita e esquerda, o qual está relacionado não à estrutura espacial, mas à própria corporeidade. A paciente acredita que vê menos à direita e tem mais sensibilidade na parte esquerda do corpo.

Também faz parte dos distúrbios na vivência do espaço orientado uma alteração na visão dos movimentos. Isso está relacionado primeiro aos movimentos próprios, de cuja possibilidade teórica a paciente I. Th. H. de fato estava consciente, mas que ela não podia mais viver como possibilidade.

“Não consigo mais sair do lugar"... "Como se eu estivesse presa num pântano". Corresponde a essa vivência de estar presa a um ponto no espaço, de não ir além, a vivência do movimento imóvel das pessoas e das coisas no espaço circundante. “Tudo se movimenta tão lentamente, que parece parado"... “Quando eu vejo alguém dirigindo uma bicicleta é como se estivesse parado". Algo parecido também aconteceu com as outras duas pacientes.

Com isso, estão designadas as alterações essenciais na vivência do espaço circundante natural e orientado. Encontramos uma perda da dimensionalidade, da plasticidade do espacial, seu empobrecimento em direção a uma adjacência plana. A articulação do espaço em perto e longe se alterou. Os primeiros planos estão mais delgados, os segundos planos mais consistentes. Ao mesmo tempo, a estimativa de distâncias está prejudicada. A energia predicativa da visão perceptiva se perde na visão "simultânea" de uma pluralidade de coisas, uma visão sem contornos e sem relações. A estrutura espacial de cima e baixo, que repousa na direção efetiva da gravidade, está suspensa, até mesmo deformada em uma vivência levitacional. Direita e esquerda também não estão mais equilibradas. Por fim, também se mostra uma alteração na percepção dos movimentos próprios e alheios, na vivência de um movimento imóvel.

Com isso, essas alterações se deixam associar aos sintomas de perda de realidade na melancolia (despersonalização - desrealização). As posições, as direções, os movimentos no espaço orientado não estão mais alinhados ao aqui absoluto do eu-corpo. A partir dele, 


\section{Hubert Tellenbach}

não vêm mais direções sensoriais, que penetram e abarcam o espaço orientado. No espaço dirigido a um fim - como nós, com E. Straus, também podemos chamar o espaço orientado, porque nele tem lugar o conflito determinado pela finalidade, entre o eu e o mundo - as finalidades perderam sua finalidade. $\mathrm{O}$ eu já não pode se apoderar do espaço de maneira ordenadora e formadora - bem como não consegue mais atingir os caracteres expressivos, dados "objetivamente", daquilo que o encontra no espaço. O "estar ciente" (Jaspers) do mundo circundante não funciona mais. Entre o eu e o mundo se colocam a distância e a escuridão.

Com essas constatações, já encontramos características do "espaço humorado" (L. Binswanger - gestimmter Raum), no qual as relações entre o eu e o mundo são incomparavelmente mais ricas e completas. Isso se torna perceptível se virmos como se correspondem o empobrecimento interior em direção do vazio e o empobrecimento do mundo em direção do vazio, como o espaço esvaziado se prolonga no vazio interior.

\section{Alterações na vivência do "espaço interior"}

Há como vivenciarmos - não nas percepções, mas na sensibilidade - as espacialidades no nosso interior corpóreo. Podemos vivenciar espacialmente as grandes cavidades corpóreas - embora somente em situações-limite consigamos sentir nela a repleção ou o vazio. Podemos ter a sensação de repleção ou vazio na barriga, de largura ou estreitamento no peito, uma cabeça carregada ou vazia. Na psicopatologia descritiva, essas situações são incluídas na "consciência corpórea", seus distúrbios, no conceito de "distúrbio vital". A vivência do "espaço interior" - se quisermos chamar assim o espacial do interior corpóreo - não teve até agora nenhuma apreciação crítica. Injustamente! Pois o espacial dessa vivência torna-se claro precisamente nos distúrbios, e é evidente sua correlação com as alterações da vivência do espaço natural.

Os caracteres vivenciais das alterações do espaço interior movem-se entre as grotescas deformações da distensão e do encolhimento (sobretudo em psicoses do espectro 


\section{A espacialidade do melancólico - Parte I}

esquizofrênico) e do congestionamento ou da repleção não natural, do estreitamento e do vazio (sobretudo na melancolia).

A paciente I, Th. H., queixa-se de uma pressão pesada sobre o peito, acredita-se estreitada por um "aperto". "No começo parecia que havia coisas demais no meio do corpo, mas depois era como se estivesse completamente vazio", diz a paciente Th. H. Essas sensações correspondem, na vivência de peso alterada, ao sentimento de situação (Befindlichkeit ${ }^{8}$ ) no espaço circundante natural. Também apontam para o espaço interior as sensações de corpo estranho, por exemplo, o globus (tão frequente na melancolia), que se quer engolir, ou empurrar para baixo com o aperto das mãos (paciente III, M. B.), ou o corpo estranho "do tamanho da ponta de um dedo" de nossa paciente I, Th. H., que precisa ser tossido para fora. A preocupação temorosa com o fechamento do espaço interior em relação ao circundante - por meio do bloqueio das vias que asseguram a troca entre os dois espaços ("nada mais passa pela garganta") - transforma-se mais tarde na vivência de uma separação insuficiente dele. "Simplesmente tudo evapora no ar. Quando tusso, a tosse se reparte rapidamente no ar, como se eu não houvesse tossido". Ou: a partir do meio do peito "tudo se reparte ${ }^{9}$ quando eu como... Quando falo, não o faço na minha linguagem natural. A partir desse lugar (o meio do peito) tudo escorre. Não se vivencia mais qualquer troca entre os espaços interiores e o circundante. $\mathrm{O}$ ar ao mesmo tempo entra por uma narina e sai pela outra. "Por dentro" também não há a sensação de resposta aos materiais ingeridos (alimentos e ar).

A paciente II, A. D., tinha uma pavorosa sensação de vazio na cabeça. Ela também fala da sensação de que seu cérebro se impelia para fora, de modo que ela teria que colocálo novamente no lugar. Alinha-se a semelhantes vivências de um vazio no espaço interior da cabeça a expressão: "Só me restou um quarto de cérebro; o resto está gagá". No caso dela, também encontramos o afastamento insuficiente entre o espaço interno e o circundante nas seguintes palavras: "Quando escrevo, também as teclas chegam ao

\footnotetext{
${ }^{8}$ N. do T.: Conceito de Heidegger utilizado para descrever a compreensão intuitiva que o homem tem do mundo como um todo.

${ }^{9}$ N. do T.: O autor apresenta aqui outra versão do relato transcrito antes, trocando sich verschieben ("deslocar$\left.\mathrm{se}^{\prime \prime}\right)$ por sich verteilen ("repartir-se").
} 


\section{Hubert Tellenbach}

cérebro". A base disso é a mesma homogeneização dos espaços interno e circundante que há na seguinte alegação da paciente I, Th. H.: “Quando um avião voa por cima de mim, agora ele zune também dentro de mim, dos ossos".

Também a paciente III, M. B., queixa-se sobre o vazio interior do corpo. Para preenchê-lo, tentou comer demais durante um tempo, de maneira inumana. Sente no peito ao mesmo tempo peso e vazio. Também nessa paciente há correspondência entre o vazio do espaço interior e o do circundante.

Isso basta quanto aos distúrbios do espaço interior. Na melancolia, eles consistem na vivência alternante, dentro das cavidades corpóreas, entre a sensação de repleção e a de corpo estranho, entre a de vazio e a de estreitamento, na vivência alternante entre o bloqueio das vias que levam ao espaço interno (vias respiratórias, esôfago, epifaringe) e sua abertura para a transição sem limites entre os espaços interior e circundante.

\section{Tentativa de "explicação" dos fenômenos}

Partimos do pressuposto que somente por meio da percepção o espacial vem até nós e pode se tornar vivência, pois ele nos está dado a priori em todo ato da sensorialidade. Uma vez que o dado tridimensional (bem como a unidade e a infinitude) é um juízo analítico ${ }^{10}$ a priori a respeito do espaço - e o que há de mais essencial para nossa vivência espacial -, devemos em primeiro lugar questionar o próprio a priori quanto à origem do espaço reduzido a duas dimensões no distúrbio espacial melancólico. Esse passo, contudo, não está apenas além das possibilidades da psicologia geneticamente compreensiva, uma vez que o a priori do espacial não é algo psíquico a partir do que o psíquico poderia surgir com evidência, mas é algo a partir do que o psíquico necessariamente se constitui.

Desse modo, podemos nos aproximar do problema da origem da vivência espacial melancólica apenas de maneira explicativa, isto é, no terreno das reflexões científico-

\footnotetext{
${ }^{10}$ N. do T.: Kant chama de analíticos os juízos que expressam algo que já está contido no sujeito a que se aplicam.
} 


\section{A espacialidade do melancólico - Parte I}

teóricas particulares. Podemos assumir que a vivência espacial melancólica tem origem em causas patológicas, que alteram o sujeito tão profundamente, que ela coloca em questão até mesmo a condição subjetiva da sensorialidade, aqueles pressupostos elementares ontológicos - de suas intuições exteriores, somente por força das quais o sujeito pode vivenciar o espaço. Contudo, essas causas não conseguiriam destruir esses pressupostos, uma vez que a sensorialidade tem sua base neles - os pacientes também "estão cientes" da vivência natural -, mas a ameaça se mostra em que a dimensionalidade normal é apenas a forma a partir da qual nós, na condição de observadores, e os pacientes, na condição de quem sabe ou se lembra, reconhecemos uma total alteração na apreensibilidade do mundo. Isso é necessariamente vivenciado como um grave estremecimento da sensorialidade natural, com dúvidas sobre a realidade do eu e do mundo, e - no sentido de Kant - como uma ameaça ao conhecimento que repousa sobre a "intuição". Recorrendo aos pressupostos da vivência, chegaríamos a uma "última instância", ao distúrbio da base do ser do sujeito.

Do ponto de vista lógico, essa consideração não exige muita reflexão: ela segue a sentença “Tudo o que acontece tem uma causa" - e, com isso, segue um juízo sintético ${ }^{11} a$ priori, no sentido de Kant. Além disso, tais considerações ganharão apoio no papel do temporal, no segundo, e mais abrangente, constituinte do psíquico; pois, na melancolia, a vivência do tempo dado a priori também se altera de diversas formas - como ocorre, por exemplo, na paciente I, Th. H., e na III, M. B. Se Kant diz: “Somente nele (isto é, no tempo) é possível toda a realidade dos fenômenos", pois "o tempo é uma condição a priori de todo fenômeno" - também dos espaciais -, parece explicável, em um distúrbio da representação temporal a priori, toda a perda de realidade, a vivência de nulidade dos melancólicos, enfim, toda a melancolia, uma vez que justamente o psíquico, na condição de um todo, a construção da realidade pessoal e material, repousa sobre os pressupostos elementares das representações a priori sem distúrbio. Espaço e tempo não são os "elementos ideais" -e a melancolia que repousa sobre a alteração deles não é a "psicose ideal"? Semelhante tentativa de basear a gênese dos sintomas de uma psicose na falência de apenas um

\footnotetext{
${ }^{11}$ N. do T.: Kant chama de sintéticos os juízos que expressam algo que não está contido no sujeito a que se aplicam.
} 


\section{Hubert Tellenbach}

fundamento do psíquico traz à mente os trabalhos de Minkowski, Straus e v. Gebsattel, nos quais obsessão e melancolia são relacionados ao distúrbio do "tempo vivido" (temps vécu), tomado como um fundamento decisivo da vida. V. Gebsattel considerava a paralisia do "movimento vital basal" do homem, de seu acontecimento intrapsíquico, o "sintoma axial" da melancolia. Esses trabalhos partem da filosofia do tempo de Bergson, Hoenigswald e Scheler. Sua fertilidade está na tentativa fascinante ${ }^{12}$ de uma fundamentação ontológica das psicoses. Contudo, do ponto de vista de uma psicopatologia baseada decisivamente nas descrições de vivências, que deseja sempre verificar seus resultados por meio de "investigações empíricas", K. Schneider tem razão quando se opõe aos autores supracitados dizendo que eles têm "interpretações filosóficas" de extraordinário engenho, mas não estão mais seguindo o "método psicológico".

No entanto, se alguém empregasse essa desqualificação metodológica contra nossas considerações, cairia numa contradição insolúvel. A compreensão do espaço (e do tempo) da psicopatologia tem base nas definições a priori de Kant ("elas são universais: nenhuma sensação, nenhum objeto sensível, nenhuma representação é exterior a essas formas" - K. Jaspers). Elas estão na base da vivência espacial tanto nos dias saudáveis como nos doentes. Se alguém tem esse ponto de partida, ele não pode recusar uma tentativa de explicação que parta dos desvios do modo fenomênico empírico dos elementos cognoscentes a priori por considerá-la um método "filosófico", isto é, não mais psicológico. Onde, nesse ponto de transição entre o abrangente (no sentido de Jaspers) e o que é cognoscível a partir da vivência, termina a filosofia e começa a psicologia? Nesse caso, o pressuposto da vivência, exigido pelo método científico da psicologia, é uma renúncia artificial, pois o a priori está categoricamente na base de cada um dos atos vivenciais espaço-temporais investigados pela psicologia. Contudo, aqui a ciência topa com um dos "aspectos" determinados e delimitados "na abrangência" (Jaspers). Se temos o espaço $a$ priori, sua estruturação elementar em unidade, infinitude e tridimensionalidade tomados como juízos analíticos a priori, a perda da tridimensionalidade deve ser relacionada a um

\footnotetext{
12 "Confesso que senti nos trabalhos de v. Gebsattel sobre os obsessivos aquela rara insinuação por meio da qual as profundezas se tornam passíveis de pressentimento, ainda que se não se deixem conhecer" (K. Jaspers).
} 


\section{A espacialidade do melancólico - Parte I}

distúrbio na consumação das representações espaciais a priori - na medida em que essa perda se transpõe para uma vivência consciente e, com isso, pode ser descrita.

O fato de que o distúrbio depressivo da vivência espacial é tão raro que até agora escapou à atenção leva a outra dificuldade principial. O método da psicopatologia descritiva exige a vivência consciente, ou seja, alterações da consciência espacial (e temporal). Com isso, nosso postulado de que a melancolia tem suas raízes em um distúrbio espaço-temporal fundamental restringir-se-ia aos poucos casos de melancolia que foram descritos - e não se suporia que têm tal distúrbio as melancolias em que essas alterações não foram vivenciadas conscientemente. A acusação de Kloos contra as concepções de Straus e v. Gebsattel (segundo a qual o distúrbio na vivência temporal se mostra tão raramente, que não se lhe pode conferir qualquer validação constitutiva) também poderia ser aplicada a nosso caso. Se quisermos insistir na inclusão de nossos casos na unidade patológica "melancolia", surgirá uma contradição insolúvel. Onde há um distúrbio na vivência espacial, podemos conceber a síndrome da melancolia como a repercussão de um estremecimento do fundamento a priori sobre todo o psíquico; onde não há semelhante vivência, o fundamento a priori estará “intacto" e, por isso, não poderá se tornar constitutivo para a melancolia. Essa contradição evoca uma série de questionamentos.

\section{Perspectivas para questionamentos}

Portanto, devemos nos abster de supor um distúrbio fundamental nos casos de melancolia paradigmática, quando as vivências espaciais (ou temporais) não remetem a ele? Isso não nos obriga a nos abster de justificadamente supor a unidade genética da síndrome da melancolia endógena? Com isso, não se mostraria uma vantagem dos trabalhos de Minkowski, Straus e v. Gebsattel, em que a gênese das psicoses são relacionadas a um "distúrbio basal", sem que ele se reflita na vivência? Ou o amadurecimento do espiritual, do mundano, a partir da corrente de devir concebida de maneira "biológica" ou "vital" é um amálgama de formas de ser humanas heterogêneas, inadequado e metodologicamente impróprio ao problema (e, desse modo, Jaspers tem 


\section{Hubert Tellenbach}

razão)? Há motivos para supor que um distúrbio fundamental permaneça oculto e não se torna passível de vivência? Pode-se supor que, além do espaço "vivenciado", há também um espaço "vivido"? A definição de Kant a respeito da articulação do espaço empírico (da “adjacência”) não se mostra, portanto, demasiado estreita para a compreensão do espacial na melancolia? Devemos partir simplesmente do conceito de espaço de Leibniz - e: ao fundamentar outros conceitos de espaço, alguém continuaria na zona isolada da psicopatologia? Não há - de acordo com o paradigma filosófico - psicopatologias em vez de "a" psicopatologia - como também há "geometrias" em lugar de "a" geometria (euclidiana), da qual Kant tratava unicamente? Há, além de uma relação causal, uma relação essencial, sob cuja condução metodológica nós nos valhamos da compreensão da melancolia não apenas a partir de uma causa fundamental, mas possamos chegar ao conhecimento não da coesão genética de todos os sintomas da melancolia, mas de sua coesão essencial? Mais ou menos da maneira com que L. Binswanger enxergava o modo de Dasein da mania - segundo a qual, o distúrbio espacial seria apenas um entre outros sintomas da melancolia, e o fato de ele ser vivenciado ou não seria de significância decisiva? A partir da pura descrição que tome como tema as alterações da sensação de espaço, ganha-se algo para a compreensão dos modos humanos de ser na melancolia? Frente às correspondências da vivência dos espaços interior e circundante, é frutífero para essa compreensão distinguir entre sujeito e mundo dos objetos, ainda que essa separação nunca perca sua justificação no pensamento? É verdade que uma psicose altera “o sujeito" primária ou exclusivamente - e só secundariamente leva a uma alteração na vivência do mundo circundante? Ou um sujeito que é primariamente privado de mundo é uma abstração artificial, à qual se deve preferir uma unidade dialética entre o eu e o mundo, fundada no ser-um primário? A tentativa de perseguir esses questionamentos será a matéria da segunda comunicação.

Tradução: Tadeu Andrade ${ }^{13}$

Revisão Técnica: Guilherme Messas

13 Tadeu Andrade é tradutor, graduado em Letras e pós-graduando na área de Letras Clássicas na Faculdade de Filosofia, Letras e Ciências Humanas da Universidade de São Paulo. 


\section{A espacialidade do melancólico - Parte I}

\section{Referências bibliográficas}

Binswanger, L. (1933) Z. Neur. 145, 598.

Fischer, F. (1930) Z. Neur. 121, 544 (1929); 124, 241.

Gebsattel, V. E. (1928) Nervenarzt 1, 275.

(1939) Gegenwartsprobleme der psychiatrisch-neurologischen Forschung, pp. 54-71. Stuttgart: Ferdinand Enke.

Jaspers, K. (1946) Allgemeine Psychopathologie. Berlin u. Heidelberg: Springer.

Kant, I. (1938) Kritik der reinen Vernunft. Leipzig: Leopold Voß.

Kloos, G. (1938) Nervenarzt 11, 225.

Leibniz, G. W. (1933) Der fünfte Brief an Clarke. In Die Hauptwerke. Leipzig: Kröner.

Minkowski, E.(1931) Wien. Klin. Wschr. 346, 380.

Schneider, K. (1929) Fortschr. Neur. 1, 127.

Straus, E. (1928) Mschr. Psychiatr. 68, 640. . (1930) Nervenarzt 3, 633. 